\title{
A rare case of spontaneous hepatic rupture in a pregnant woman
}

\author{
Xiao Zhou, Meng Zhang, Zhuang Liu, Meili Duan and Lei Dong ${ }^{*}$ (D)
}

\begin{abstract}
Background: Spontaneous hepatic rupture in pregnancy is a rare and life-threatening event during the perinatal period. Case presentation: We report a case of a 33-year-old woman with $36+6$ weeks' gestation that present with elevated blood pressure before delivery, who was admitted to our hospital due to irregular abdominal pain. Diagnosed with abdominal paracentesis, the emergent caesarean section and laparotomy were performed. Postoperatively, the patient experienced 22-day intensive therapy in ICU and was transferred to the General Surgery Department in good physical condition without post-operative complications.
\end{abstract}

Conclusions: This case indicates that making an accurate and timely diagnosis and taking multidisciplinary approach contribute to a successful clinical outcome.

Keywords: Perinatal mortality, Pregnancy complications, Rupture, Spontaneous, Fatty liver

\section{Background}

Spontaneous hepatic rupture in pregnancy is a rare condition and carries a high maternal and perinatal mortality [1]. It is usually associated with hepatic hemangiomata, hepatic metastases from choriocarcinoma, or some unknown causes. Its sudden appearance and potentially fatal outcome make it an important diagnostic and therapeutic challenge.

We reported a successfully treated case of spontaneous hepatic rupture in a pregnant woman. It emphasizes the need for the early diagnosis as well as the timely surgical management and the postoperative monitoring of patients in the intensive care unit. The relevant literature is also reviewed.

\section{Case presentation}

A 33-year-old primigravida woman, a body mass index of $31 \mathrm{~kg} / \mathrm{cm} 2$, was admitted to the emergency department at $36+6$ weeks gestation with abdominal pain that had lasted for $6 \mathrm{~h}$. She did not have a history of trauma. Her antenatal period had been uneventful except for one episode of hypertension (141/84 mmHg). Physical examination revealed a blood pressure of $102 / 62 \mathrm{~mm} / \mathrm{Hg}$, a heart rate of 80 beats $/ \mathrm{min}$ and a temperature of $36.6{ }^{\circ} \mathrm{C}$.

\footnotetext{
* Correspondence: 18618334341@163.com

Department of Intensive Care Unit, Beijing Friendship Hospital, Capital

Medical University, No. 95 Yong-An Road, Xi Cheng District, Beijing 100050, China
}

(c) The Author(s). 2018 Open Access This article is distributed under the terms of the Creative Commons Attribution 4.0 International License (http://creativecommons.org/licenses/by/4.0/), which permits unrestricted use, distribution, and reproduction in any medium, provided you give appropriate credit to the original author(s) and the source, provide a link to the Creative Commons license, and indicate if changes were made. The Creative Commons Public Domain Dedication waiver (http://creativecommons.org/publicdomain/zero/1.0/) applies to the data made available in this article, unless otherwise stated.
Blood tests showed hemoglobin of $95 \mathrm{~g} / \mathrm{L}$,Hematocrit of $28.9 \%$, platelet count of $111 \times 10^{9} / \mathrm{L}$ (reference range, $\left.110-300 \times 10^{9} / \mathrm{L}\right)$, reticulocyte count of $0.0525 \times 10^{12} /$ $\mathrm{L}\left(\right.$ reference range, $0.014-0.09 \times 10^{12} / \mathrm{L}$ ), liver enzymes with an alanine aminotransferase of $281 \mathrm{U} / \mathrm{L}$, aspartate aminotransferase of $392 \mathrm{U} / \mathrm{L}$, lactate dehydrogenase of $525 \mathrm{U} / \mathrm{L}$, total bilirubin levels of $19 \mu \mathrm{mol} / \mathrm{L}$ (reference range, 3.42-17.1umol/L), and normal alpha fetoprotein. Serological markers of hepatitis B and hepatitis C virus were negative. Ultrasound scan showed that fetal heart beats could not be found and free abdominal fluid was present. There were no images suggesting placental abruption. Ultrasound-guided intra-abdominal puncture revealed active intraperitoneal bleeding.

In less than $3 \mathrm{~h}$ of admission, an emergency laparotomy was performed and a dead fetus was delivered by cesarean section. No evidence of placental abruption or active intrauterine bleeding was detected. Exploration of the ovarian tubes and ovaries revealed no bleeding or neoplasm. Two liters of hemoperitoneum was removed from abdominal cavity. Active hemorrhage came from rupture of the right lobe of the liver which appeared fatty liver. Direct hemostasis was not achievable because the liver was edematous and was ruptured during the performance of sutures. Thus perihepatic packing was done by seven large gauze packs and hemostatic sponges were used to compress the bleeding 
lesions. Throughout the laparotomy, intraoperative bleeding was $2000 \mathrm{~mL}$ and the patient received 8 units of RBC and $1200 \mathrm{ml}$ of plasma.

The patient was transferred to the ICU after surgery to continue resuscitation with intravenous fluids and vasoactive support. The following day in ICU, she had high fever and developed the acute kidney injury and severe acute respiratory distress syndrome. She was managed by massive blood transfusion, mechanical ventilation, renal replacement therapy and antibiotic treatment. Intra-abdominal pressure was maintained between 7.5 and $11.3 \mathrm{mmHg}(1-1.5 \mathrm{KPa})$ by abdominal binder.

A second laparotomy was performed on the 6th postoperative day. A large hematoma and rupture of the right liver lobe were visible after removing the gauze packs (Fig. 1a), which was still bleeding (Fig. 1b). The patient was treated with argon laser to stop bleeding (Fig. 1c). Moreover, one drain was left in the abdomen. Postoperatively, ultrasound showed perihepatic and pelvic free fluid that required percutaneous drainage. Abdominal computed tomography (CT) scan (Fig. 2) revealed perihepatic effusion with laceration of the right liver lobe and hypo-density of fluid in the peritoneal cavity. Decreasing in volume of the perihepatic effusion was observed by subsequent CT scan (Fig. 2). After 22 days of recovery in ICU, the patient was transferred to the surgical department where she remained for further 3 weeks with regular post-operative course. She was discharged in normal physical condition after 45 days.

\section{Discussion and conclusions}

Spontaneous hepatic rupture in pregnancy, which was first described by Abercrombie in 1984, is a rare condition associated with high maternal and perinatal mortality [1], with its incidence ranging from 1 in 45,000 to1 in 225,000 deliveries [2]. A recent literature review of hepatic rupture revealed a maternal mortality rate of $39 \%$ [3] and a perinatal mortality rate of $42 \%$ [4]. Spontaneous hepatic rupture is commonly caused by hepatic hemangiomata, hepatocellular carcinoma, hepatic adenoma, of which were reported to be pregnancy-related but rare [5]. Other causes arehepatic metastases from choriocarcinoma, focal nodular hyperplasia, peliosishepatis, trauma, infection (malaria, syphilis, amoebic abscess), aneurysms; granulomas, the use of cocaine during pregnancy, anabolic steroid therapy, systemic amyloidosis [6] and unknowns [7, 8]. Hepatic rupture in pregnancy usually is associated with pre-eclampsia, eclampsia, or Hemolysis Elevated Liver enzymes and Low Platelet count (HELLP) syndrome [9]. Spontaneous hepatic rupture in uncomplicated pregnancy also has been reported but is extremely rare [10]. The presenting symptoms and signs of liver bleeding are subtle and non-specific, the most common are abdominal pain, shoulder pain and vomiting. Thus, a high index of clinical suspicion is necessary and emergency ultrasonography, CT, or magnetic resonance imaging should be considered to reach the diagnosis of spontaneous hepatic rupture in a timely manner. As a pregnant woman presents with a sudden onset of unexplained, severe abdominal pain, spontaneous rupture of the liver should be suspected.

Hepatic rupture requires immediate laparotomy to stop bleeding, therapeutic options involves perihepatic packing, placement of sponges or absorbable mesh, fibrin glue, argon laser coagulation and hepatic artery ligation. Partial liver resection or even liver transplantation has been described in the literatures. The outcome of patients with spontaneous hepatic rupturegreatly depends on the etiology and severity of the hemorrhage $[11,12]$.

In this case, the patient had no history of trauma, excessive alcohol consumption, or use of hepatotoxic

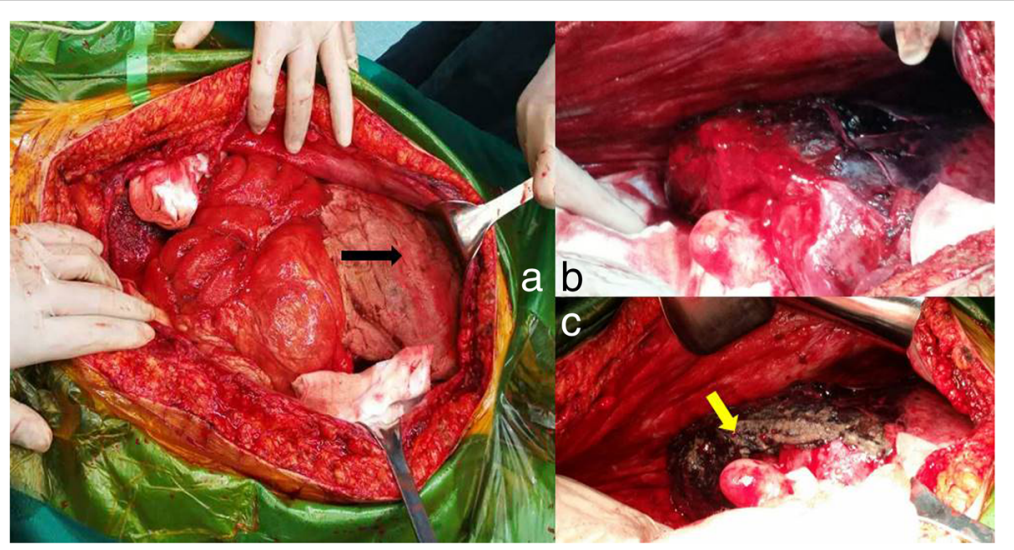

Fig. 1 The 2nd operation findings. a liver packing (black arrow shows gauzes). b liver hemotoma. c Argon laser to stop bleeding (yellow arrow shows laser-coagulation) 

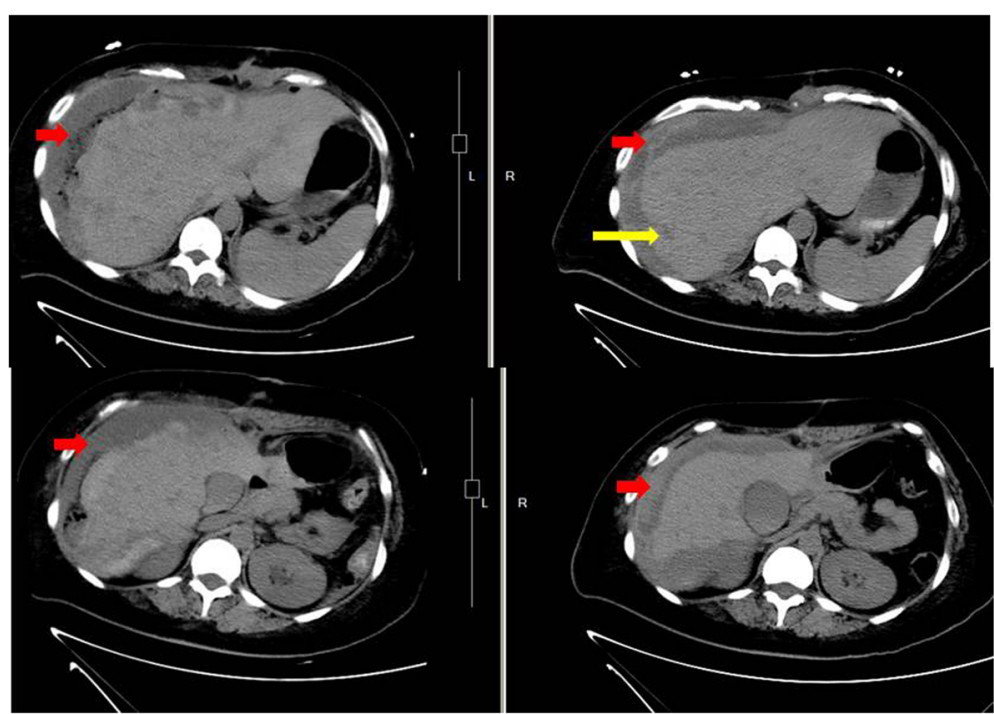

Fig. 2 Abdominal CT scans on the 3rd day (left) and 13th day (right) post the second surgery. Red arrows (hypodense collection) show perihepatic effusion. Yellow arrow shows the ruptures of the liver

medications, moreover, she did not have pre-eclampsia or eclampsia during this pregnancy, tumor biomarkers as well as clinical tests of hepatitis $B$ and $C$ virus infection were negative. Liver lesions were not visible at operation or with imaging. There was insufficient evidence for the diagnosis of HELLP syndrome: the platelet count was marginally low even with massive hemorrhage, tests of hemolysis were negative (serum indirect bilirubin, reticulocyte count, Coombs test, and Ham's test), and liver enzymes before acute hemorrhage were mildly elevated. Nevertheless, HELLP syndrome cannot be totally excluded due to the presence of hypertension. HELLP syndrome is considered as a risk factor for hepatic rupture in pregnancy. Vigil-De et al. reported that it was present in $92.8 \%$ of cases in their series during the past two decades [12]. With this case of a high BMI, fatty liver was suspected during laparotomy but no evidence from the biopsy yet. A few cases of fatty liver disease associated with hepatic rupture have been reported, the incidence was about 1 in 13,000 pregnancies [13].

A large hematoma was on the right lobe of the liver in this patient. Perihepatic packing was carried out to control the bleeding in this case, however, she remained at risk for complications, such as intraperitoneal infection. For patient with continued bleeding after the first surgical operation, ICU assistance played a valuable role on the recovery during the post-operative course. The right hepatic lobectomy was another choice for the surgeon when hemorrhage remained uncontrolled, which probably led to postoperative liver dysfunction. Hence, an effort should be made to gain hemostatic control while avoiding large resections as much as possible.
In conclusion, spontaneous hepatic rupture in pregnancy is rare but life-threatening. A high level of alertness for the diagnosis aided by timely ultrasonography and CT scan is critical to prompt intervention, which requires multidisciplinary approach to achieve a successful outcome.

\section{Abbreviations}

CT: Computer tomography; HELLP: Syndromehemolysis elevated liver enzymes and low platelet syndrome; ICU: Intensive care unit

\section{Acknowledgements}

The authors give special thanks to Professor Jingfeng Liu who guided this work.

\section{Funding}

Not applicable.

\section{Availability of data and materials}

All data generated or analysed during this study are included in this published article.

\section{Authors' contributions}

LD and MLD made the treatment strategies to the patient. XZ, MZ and ZhL underwent treatments and read the literature. $X Z$ was a major contributor in writing the manuscript. All authors read and approved the final manuscript.

Ethics approval and consent to participate

This study was approved by the Hospital Ethics Committee,No.2017-P2-092-01.

The patient was treated according to standard care.

\section{Consent for publication}

The patient has provided written informed consent for the publication of this case report and any accompanying images.

\section{Competing interests}

The authors declare that they have no competing interests.

\section{Publisher's Note}

Springer Nature remains neutral with regard to jurisdictional claims in published maps and institutional affiliations. 
Received: 9 October 2017 Accepted: 22 March 2018

\section{Published online: 10 April 2018}

\section{References}

1. Poo JL, Gongora J. Hepatic hematoma and hepatic rupture in pregnancy. Ann Hepatol. 2006;5(3):224-6.

2. Wicke C, Pereira PL, Neeser E, et al. Subcapsular liver hematoma in HELLP syndrome: evaluation of diagnostic and therapeutic options-a unicenter study. Am J Obstet Gynecol. 2004;190(1):106-12.

3. Reck T, Bussenius-Kammerer M, Ott $R$, et al. Surgical treatment of HELLP syndrome-associated liver rupture-an update. Eur J Obster Gynecol Reprod Biol. 2001;99(1):57-65.

4. Marsh FA, Kaufmann SJ, Bhabra K. Surviving hepatic rupture in pregnancy-a literature review with an illustrative case report. J Obstet Gynecol. 2003; 23(2):109-13.

5. Srinivasa S, Lee WG, Aldameh A, et al. Spontaneous hepatic haemorrhage: a review of pathogenesis, aetiology and treatment. Int Hepato-PancreatoBiliary Assoc. 2015;17:872-80.

6. Suda T, Oguri HA. Case of primary amyloidosis with spontaneous hepatic rupture. Nihon Shokakibyo Gakkai Zasshi. 2017;114(6):1039-45.

7. Sommacale D, Palladino E, Tambya EL, et al. Spontaneous hepatic rupture in a patient with peliosishepatis: a report of one case. Int J Surg Case Rep. 2013;4(5):508-10.

8. Sommacale D, Palladino $E$, Esther $L$, et al. Spontaneous hepatic rupture in a patient with peliosishepatis: a report of one case. Int J Surg Case Rep. 2013:4(5):508-10.

9. Kjell Haram, Einar Svendsen, Ulrich Abildgaard. A Review. Am J Forensic Med Pathol. BMC Pregnancy Childbirth 2009; 9: 8.

10. Abdi S, Cameron IC, Nakielny RA, et al. Spontaneous hepatic rupture and maternal death following an uncomplicated pregnancy and delivery. BJOG. 2001;108(4):431-3.

11. Miguelote RF, Costa V, Vivas J, et al. Postpartum spontaneous rupture of a liver hematoma associated with preeclampsia and HELLP syndrome. Arch Gynecol Obstet. 2009;279(6):923-6.

12. Vigil-De Gracia P, Ortega-Paz L. Pre-eclampsia/eclampsia and hepatic rupture. Int J Gynaecol Obstet. 2012;118(3):186-9.

13. Pereira SP, O'Donohue J, Wendon J, et al. Maternal and perinatal outcome in severe pregnancy-related liver disease. Hepatology. 1997;26:1258-62.

\section{Submit your next manuscript to BioMed Central and we will help you at every step:}

- We accept pre-submission inquiries

- Our selector tool helps you to find the most relevant journal

- We provide round the clock customer support

- Convenient online submission

- Thorough peer review

- Inclusion in PubMed and all major indexing services

- Maximum visibility for your research

Submit your manuscript at www.biomedcentral.com/submit 